\title{
Grifolin induces autophagic cell death by inhibiting the Akt/mTOR/S6K pathway in human ovarian cancer cells
}

\author{
XIAOXIA CHE ${ }^{1}$, HONG YAN $^{1,2}$, HENGZI SUN $^{1}$, SAMINA DONGOL $^{1}$, \\ YILIN WANG ${ }^{1}$, QINGTAO LV $^{3 *}$ and JIE JIANG ${ }^{1 *}$ \\ ${ }^{1}$ Department of Gynecology, Qilu Hospital of Shandong University, Jinan; ${ }^{2}$ Women and Children's Hospital, \\ Decheng, Dezhou, Shandong; ${ }^{3}$ Shandong University of Traditional Chinese Medicine, Jinan, Shandong, P.R. China
}

Received January 8, 2016; Accepted April 14, 2016

DOI: $10.3892 / o r .2016 .4840$

\begin{abstract}
Grifolin, a secondary metabolic product isolated from the mushroom Albatrellus confluence, has been reported to possess antitumor activities in various tumors. To date, no report exists on the role of autophagy in grifolin-treated human ovarian cancer cells. In the present study, we investigated the effect and the mechanism of autophagy in ovarian cancer. Ovarian cancer cell lines A2780 and SKOV3 were treated with grifolin. Cell proliferation was assessed by MTT assay and the autophagic effect was determined using flow cytometry, electron microscopy, immunofluorescence staining and GFP-LC3 puncta formation assay. The expression of autophagy markers and the main autophagy-associated Akt/ mTOR/S6K pathway proteins were measured by western blot analysis. MTT assay indicated that grifolin inhibits the proliferation of human ovarian cancer cell lines A2780 and SKOV3. Flow cytometry, electron microscopy, immunofluorescence and GFP-LC3 puncta formation assay proved that grifolin induces autophagic cell death in human ovarian cancer. The results of the western blot analysis suggested that grifolin treatment leads to upregulation of autophagy markers LC3B, Atg7, Beclin-1 along with downregulation of P62. In addition, the proteins of the pathways p-Akt, p-mTOR, p-p70S6K and $\mathrm{p}-4 \mathrm{E}-\mathrm{BP} 1$ were downregulated while the total of these proteins remained unaffected. The present study indicated that grifolin could induce autophagic cell death in human ovarian cancer by inhibiting the Akt/mTOR/S6K pathway.
\end{abstract}

Correspondence to: Professor Jie Jiang, Department of Obstetrics and Gynecology, Qilu Hospital of Shandong University, 107 Wenhua Xi Road, Jinan, Shandong 250012, P.R. China

E-mail: qljiangjie@sdu.edu

Professor Qingtao Lv, Shandong University of Traditional Chinese Medicine, 4655 Daxue Road, Jinan, Shandong 250355, P.R. China

E-mail: luqingtao9@163.com

*Contributed equally

Key words: ovarian cancer, grifolin, autophagy, Akt/mTOR/S6K pathway

\section{Introduction}

Ovarian cancer is regarded as the deadliest gynecological cancer with the highest mortality rate worldwide. In the year 2015, more than 21,290 new cases and 14,180 deaths were reported all over the world (1). Traditional methods with chemotherapy after surgery may cause unwanted side-effects and drug resistance in patients. Therefore, it is necessary to develop more effective drugs against ovarian cancer. In recent studies, natural agents have been widely used for cancer therapy. Grifolin (2-trans, trans-farnesyl-5-methylresorcinol), a secondary metabolite extracted from the mushroom Albatrellus confluens, is an antibiotic belonging to basidiomycota $(2,3)$. Several mechanisms have been reported, including inhibition of G1 phase cell cycle (4-6), promotion of apoptosis proteins $(7,8)$ suppression of cell metastasis (9) which have been proposed to explain grifolin's antitumor effects. However, the other mechanisms of the drug's antitumor effects have remained unclear.

In the present study, we investigated the autophagic effect of grifolin on human ovarian cancer cell lines A2780 and SKOV3 in vitro. We found that grifolin inhibited cell growth in the two types of cells through inducing autophagic cell death via Akt/mTOR/S6K pathway. These results suggest that grifolin could be a meaningful therapeutic for the treatment of human ovarian cancer.

\section{Materials and methods}

Cell lines and culture. The human ovarian cancer cell line A2780 and SKOV3 were purchased from the American Type Culture Collection (ATCC; Manassas, VA, USA) and were cultured in RPMI-1640 medium with $10 \%$ fetal bovine serum (FBS). All cells were maintained at $37^{\circ} \mathrm{C}$ in a humidified atmosphere containing $5 \% \mathrm{CO}_{2}$.

Reagents and antibodies. Grifolin was kindly provided by Kunming Institute of Botany, the Chinese Academy of Science and prepared at a concentration of $100 \mathrm{mmol} / \mathrm{l}$ stock solution in dimethyl sulfoxide (DMSO). Both chloroquine disphosphate (CQ) and acridine orange were obtained from Abcam (Cambridge, UK). The antibodies to p-Akt, Akt, p-mTOR, mTOR, p-p70S6K, p70S6K, p-S6, S6, p-4E-BP1 and 4E-BP1 
were all purchased from Cell Signaling Technology (Danvers, MA, USA), the antibodies to LC3B, P62, Atg7, Beclin-1 and $\beta$-actin were obtained from Abcam. The cell culture media and other reagents were obtained from HyClone Laboratories (Logan, UT, USA).

Cell viability assay. Cell viability was measured by MTT assay. The A2780 and SKOV3 cells were seeded at a density of (4-5) $\times 10^{3}$ on 96-well plates and was allowed to adhere overnight. The cells were then treated with various concentration of the drugs $(0,20,40,60,80$ and $100 \mu \mathrm{M})$ to cells for 24 , 48 and $72 \mathrm{~h}$. At indicated time-points, the cells in the 96-well plate were incubated with $20 \mu \mathrm{l} \mathrm{MTT}$ and after $4 \mathrm{~h}$ at $37^{\circ} \mathrm{C}$. The formazan product was dissolved in $100 \mu 1 \mathrm{DMSO}$ and evaluated at $490 \mathrm{~nm}$ with a microplate reader called infinite M200 PRO (Bio-Rad Laboratories, Hercules, CA, USA.)

Flow cytometric analysis of acidic vesicular organelles (AVOs). The ovarian cancer cells were treated with grofolin with different concentrations $(0,25,50$ and $75 \mu \mathrm{M})$ for $24 \mathrm{~h}$ and then stained with acridine orange $(1 \mu \mathrm{g} / \mathrm{ml})$ in PBS at $37^{\circ} \mathrm{C}$ for 15 min in dark. Then the cells were washed with cold PBS twice and re-suspended in PBS for analysis in $1 \mathrm{~h}$. The data were analyzed by CellQuest software.

Immunofluorescence staining. Analysis of LC3B protein localization: the cells were plated in 24-well plates and treated with $50 \mu \mathrm{M}$ grifolin for $24 \mathrm{~h}$. The cells were then fixed with $4 \%$ paraformaldehyde for $15 \mathrm{~min}$ at room temperature and were permeabilized with $0.2 \%$ Triton $150-200 \mu 1$ in PBS for $10 \mathrm{~min}$. After that, the cells were blocked with indicated anti-LC3B antibody (1:200) overnight and related secondary antibody (1:250) for $1 \mathrm{~h}$ in dark and then stained with 4,6-diamidino-2-pheny-lindole (DAPI) for $5 \mathrm{~min}$ in dark and at room temperature. At last, the fluorescence images were observed using a DP71 fluorescence microscope (Olympus, Tokyo, Japan).

Electron microscopy. The grifolin-treated cells were used to detect the induction of autophagy in ovarian cancer. The cells were treated with $50 \mu \mathrm{M}$ grifolin for $48 \mathrm{~h}$ and harvested by trypsinization and then fixed with cold fixative containing $2.5 \%$ glutaraldehyde and $2 \%$ paraformaldehyde in $0.1 \mathrm{M}$ cacodylate buffer. Then the samples were post-fixed in $1 \%$ osmium tetroxide buffer $\left(\mathrm{OsO}_{4}\right)$. We observed the representative areas (90 $\mathrm{nm}$ thin sections were cut) with a JEM-1010 transmission electron microscope (JEOL USA, Inc., Peabody, MA, USA) at $80 \mathrm{kV}$.

Western blot analysis. Vehicle- or drug-treated cells were lysed in a mixed buffer which contained RIPA, NaF, PMSF, and the supernatants were collected and the protein levels were measured. Protein $(20 \mu \mathrm{g})$ were resolved by 12 or $10 \%$ SDS-PAGE and transferred to PVDF membranes (Immobilon $\mathrm{P}$; Millipore, Bedford, MA, USA). After blocking for $2 \mathrm{~h}$ using 5\% non-fat milk, the stripes were incubated with the indicated primary antibodies overnight at $4^{\circ} \mathrm{C}$. This was followed by incubation with secondary antibodies at room temperature for 1-2 $\mathrm{h}$. The protein signals were then detected by ImageQuent LAS 4000.
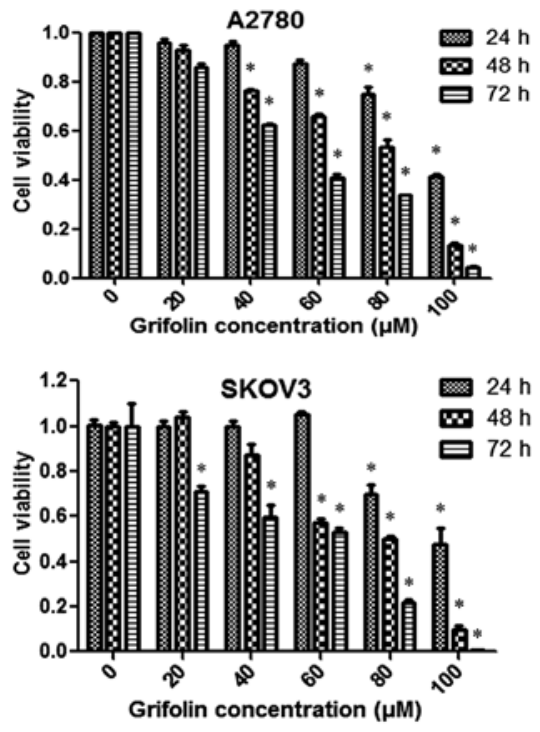

Figure 1. Anti-proliferative effects of grifolin on human ovarian cancer cell lines A2780 and SKOV3. Cells were seeded in 96-well with varying concentrations of grifolin $(0,20,40,60,80$ and $100 \mu \mathrm{M})$ for 24,48 and $72 \mathrm{~h}$. Then cell proliferation rate was assessed by MTT assay. Results are representative of three independent experiments. Compared with control group $(0 \mu \mathrm{M}){ }^{*} \mathrm{P}<0.05$.

GFP-LC3 puncta formation assay. Cells were plated in 6 -well cell culture plates at the confluence of $1 \times 10^{5}$ cells/well and incubated at $37^{\circ} \mathrm{C}$ temperature with $5 \% \mathrm{CO}_{2}$ overnight. Then the cells were transfected with GFP-LC3 plasmid using Olifectamine and Opti-MEM medium according to the manufacturer's protocol.

shRNA transfection. ShRNA was used to silence LC3B protein expression in A2780 and SKOV3 cells. Establishment of A2780-plko.1-shLC3B, A2780-plko.1-NC, SKOV3-plko.1shLC3B and SKOV3-plko.1-NC cell lines (shRNA-Forward primer CCGGCGCTTACAGCTCAATGCTAATCTCGA GATTAGCATTGAGCTGTAAGCGTTTTTG and shRNAReverse primer AATTCAAAAACGCTTACAGCTCAATGC TAATCTCGAGATTAGCATTGAGCTGTAAGCG).

Statistical analysis. T-test and one-way ANOVA were performed to determine significance by using the software SPSS 18.0. Statistical significance was determined at $\mathrm{P}<0.05$. All the experiments were performed in triplicate.

\section{Results}

Grifolin induces cell proliferation in human ovarian cancer cell lines. We examined the effect of grifolin on cell viability of A2780 and SKOV3 cells which did decrease cell viability in the two cell lines in a dose- and time-dependent manner, as shown in Fig. 1.

Grifolin induces autophagy in ovarian cancer cell lines. The induction of autophagy by grifolin was confirmed by flow cytometry using acridine orange staining. As shown in Fig. 2, grifolin-treated cells increased formation of AVOs in a dosedependent manner.

In the grifolin-treated cells, autophagy could cause ultrastructural changes. In Fig. 3, we observed autophagy in 

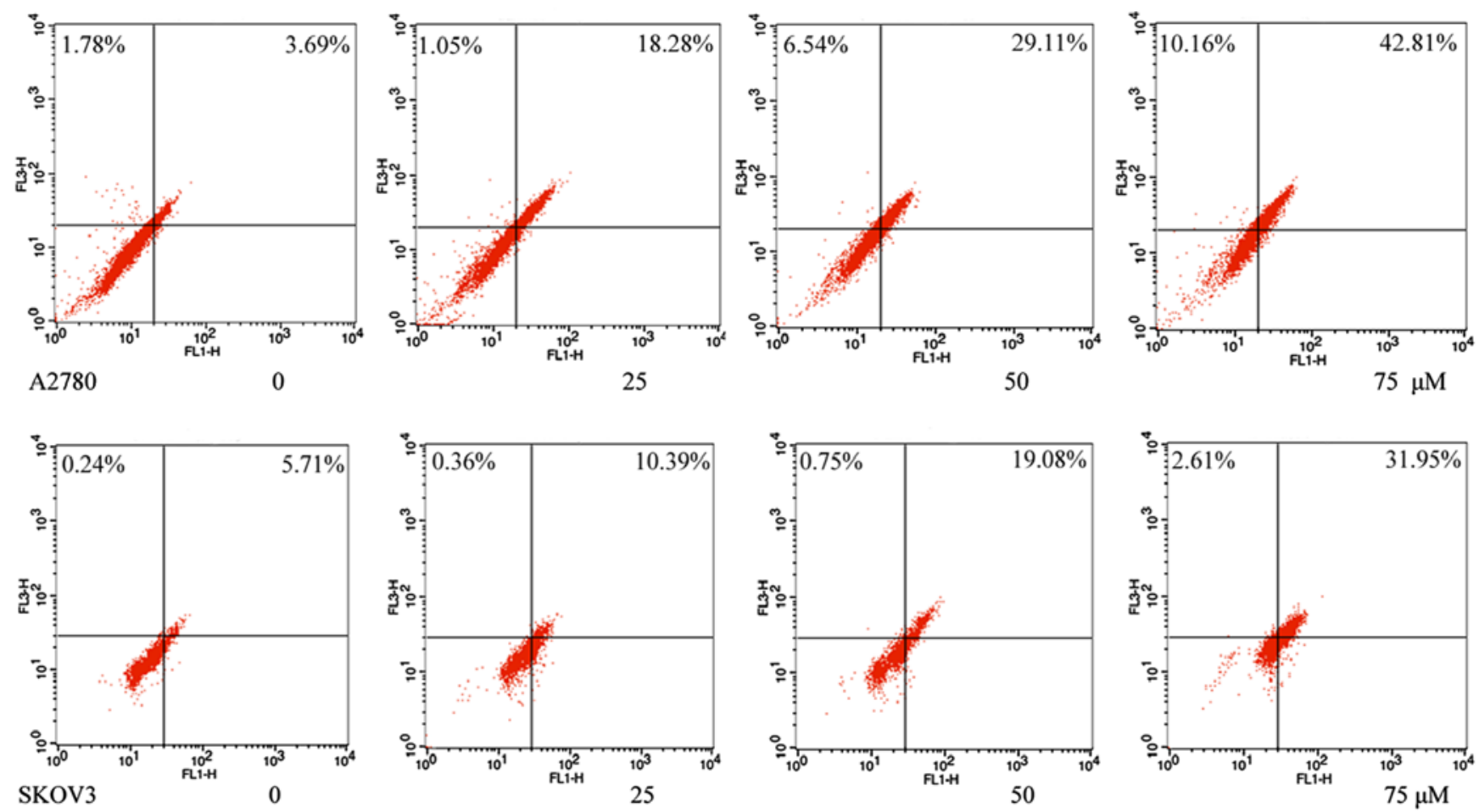

Figure 2. A2780 and SKOV3 cells were treated with different concentrations of grifolin $(0,25,50$ and $75 \mu \mathrm{M})$ for $24 \mathrm{~h}$ and then harvested. The suspended cells were marked with acridine orange and quantified using flow cytometry. FL1-H shows green color and Fl1-H indicates red color (AVO). Cells in upper and left quadrants were considered AVO-positive. Results are the mean \pm SD of duplicate samples and repeated three times with similar results experiments. Compared with control group $(0 \mu \mathrm{M}){ }^{*} \mathrm{P}<0.05$.
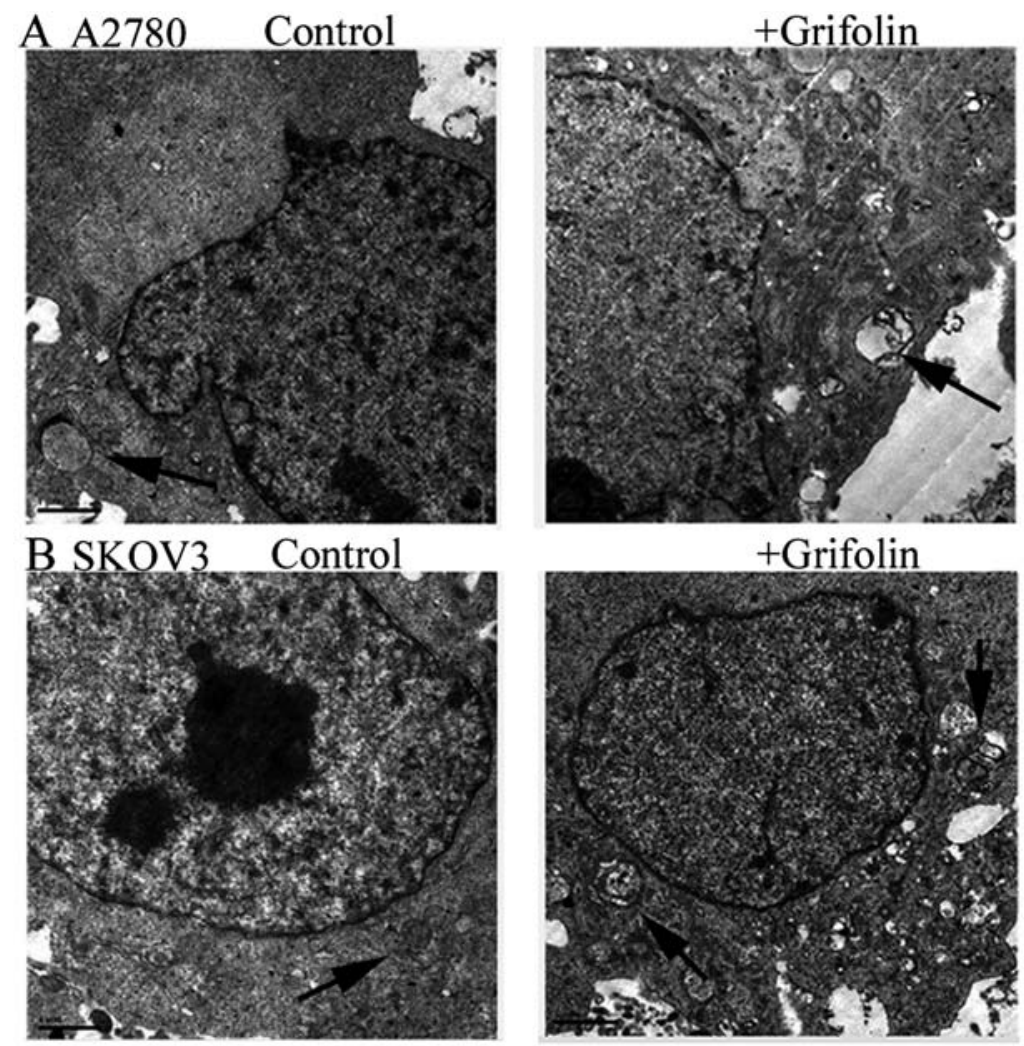

Figure 3. A2780 and SKOV3 cells were treated with or without $50 \mu \mathrm{M}$ grifolin for $48 \mathrm{~h}$ using representative electron micrographs.

grifolin-treated cells by transmission electron microscopy. The cells were treated with $50 \mu \mathrm{M}$ grifolin for $48 \mathrm{~h}$, after which, we were able to observe the characteristics of cells undergoing autophagy. 


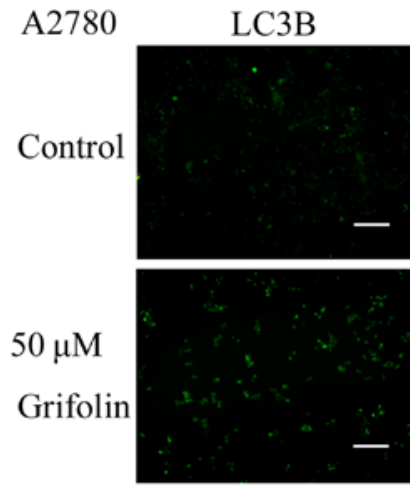

SKOV3
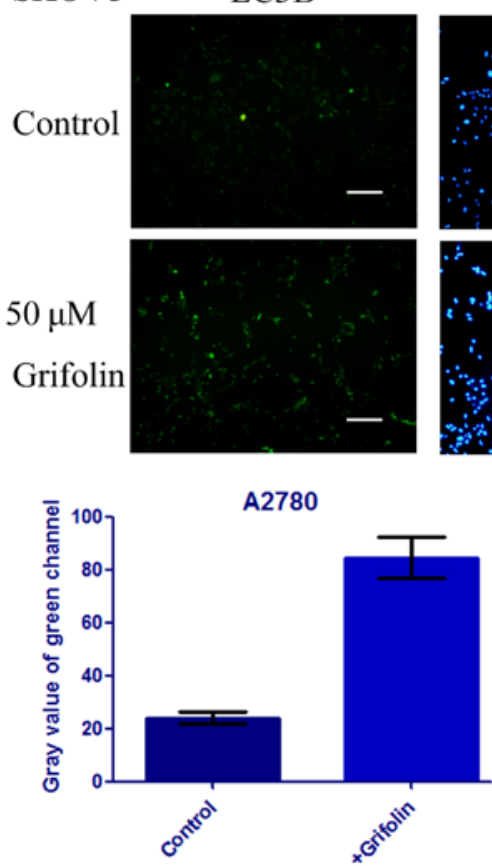

DAPI
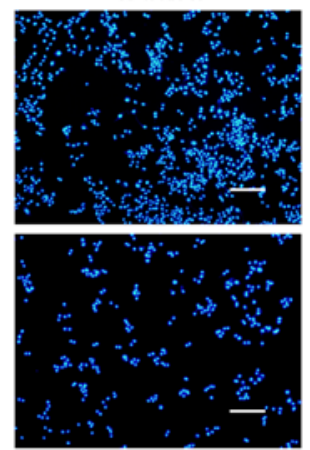

DAPI
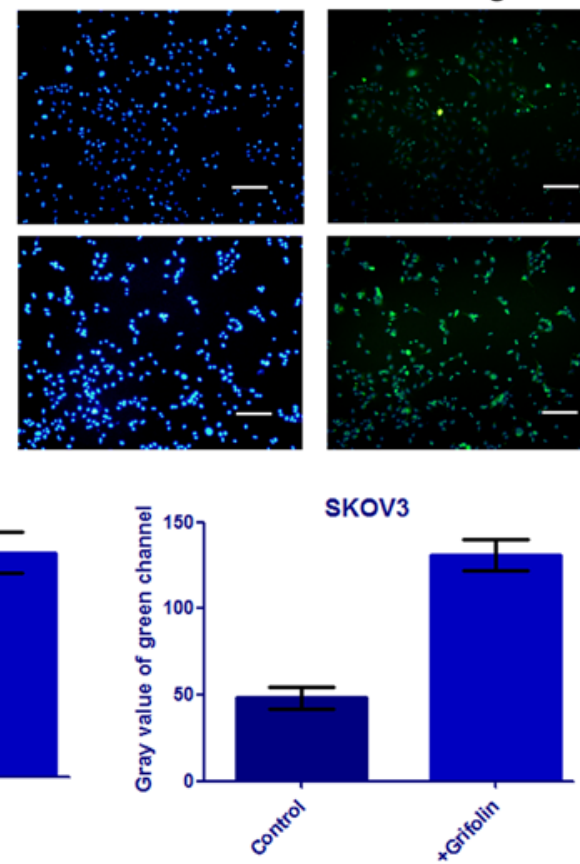

Figure 4. A2780 and SKOV3 cells were treated with or without $50 \mu \mathrm{M}$ grifolin for $24 \mathrm{~h}$ and stained with the LC3B antibody by immunofluorescence staining. Bars, $100 \mu \mathrm{m}$.

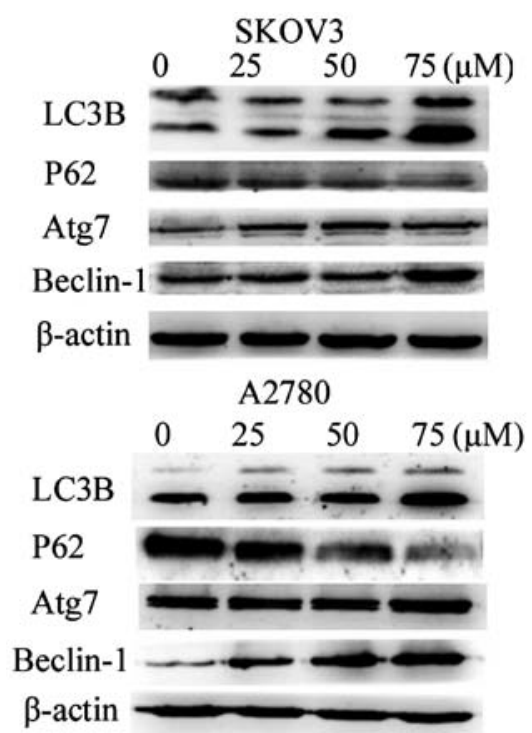

Figure 5. Western blot analysis was used to detect well-known autophagy markers. Cells were harvested after being exposed to various concentrations of grifolin $(0,25,50$ and $75 \mu \mathrm{M}) 24 \mathrm{~h}$. Data were obtained from three independent experiments. $\beta$-actin was used as a loading control.

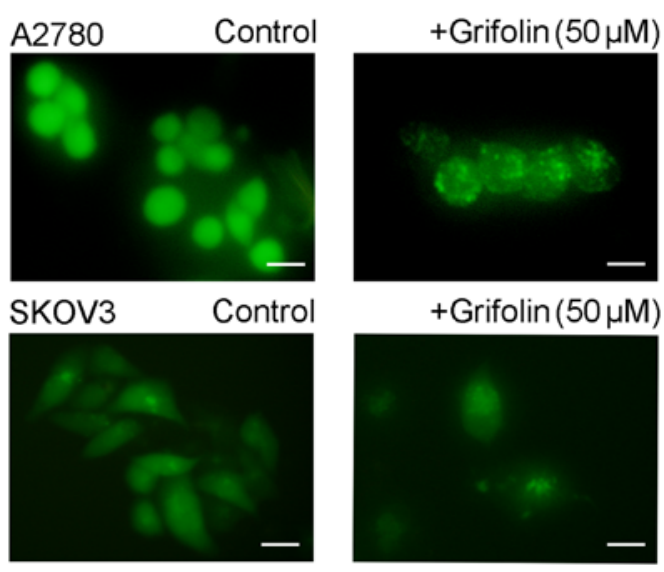

Figure 6. A2780 and SKOV3 cells were transfected with a GFP-LC3 plasmid and then treated with or without $50 \mu \mathrm{M}$ grifolin for $24 \mathrm{~h}$. The cells were observed under a fluorescence microscope. Bars, $25 \mu \mathrm{m}$.

It has been well-established that the microtubule-associated protein 1 light chain 3 (LC3) is a protein associated with the autophagosomal membrane (10). After being treated with 

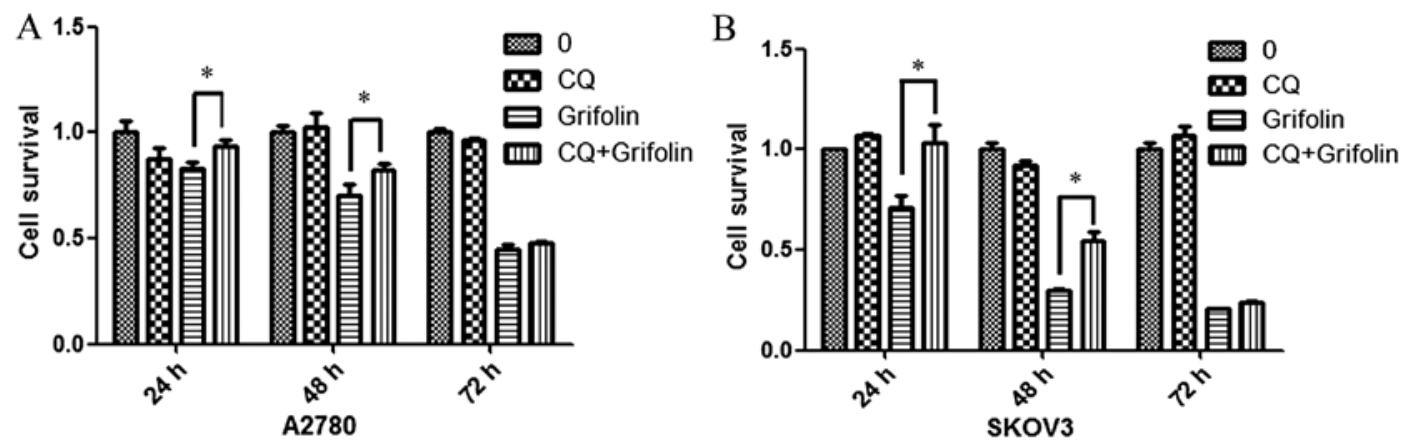

Figure 7. A2780 and SKOV3 cells were incubate in a 96-well plate with $10 \mu \mathrm{M} \mathrm{CQ}$ before being treated with grifolin. The cell survival rate was measured using MTT assay. Representative data from three independent experiments are shown. ${ }^{*} \mathrm{P}<0.05$.
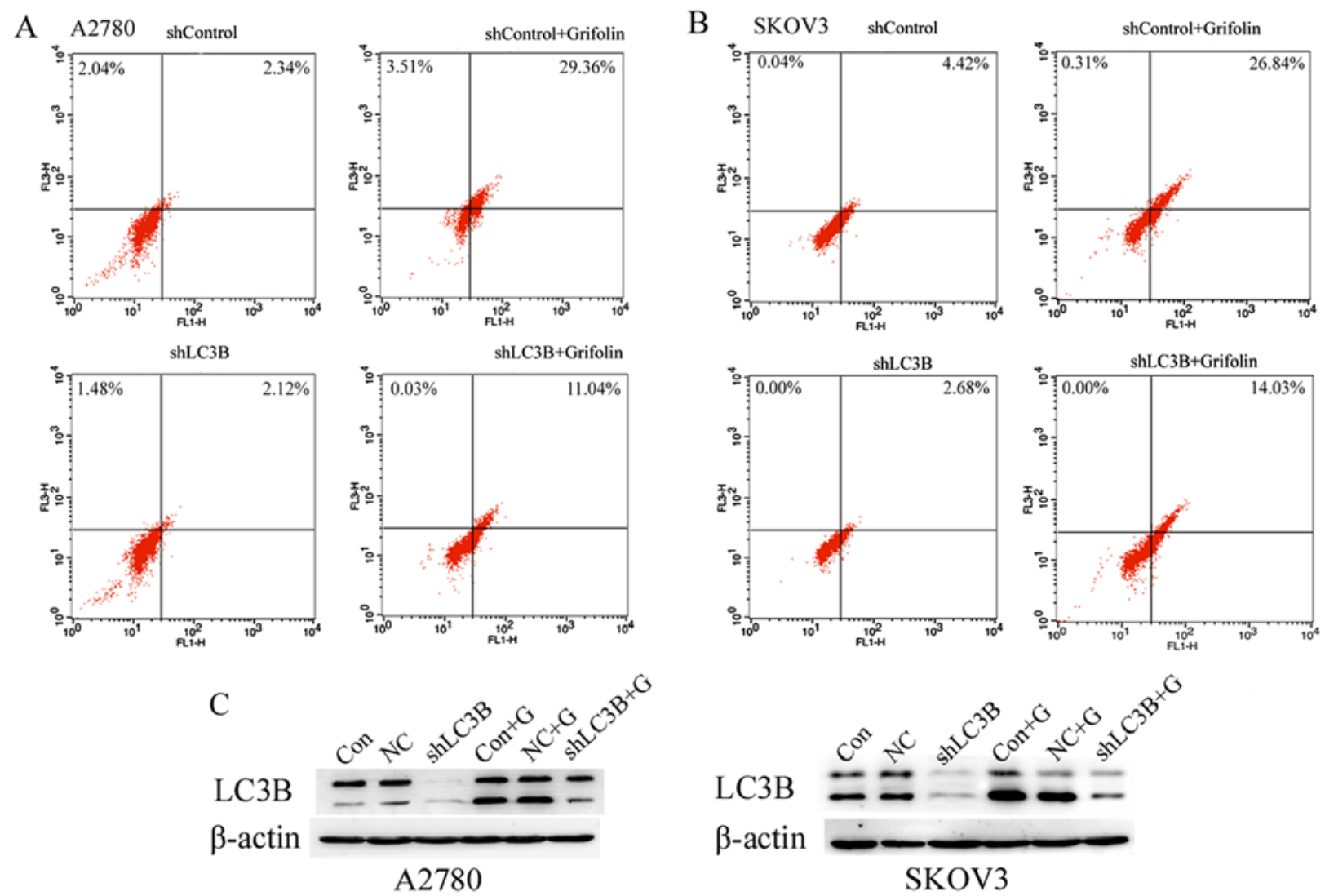

Figure 8. (A and B) LC3B was knocked down by shRNA. A2780 and SKOV3 cells were transfected with shLC3B. shControl was used as the negative control (NC). The cells were treated with or without grifolin for $24 \mathrm{~h}$ and then harvested. Then the suspended cells were marked with acridine orange and quantified via flow cytometry. (C) Con, normal cells, and $\mathrm{NC}$ was used as the negative control, $\mathrm{G}$, grifolin. Cells were harvested after being exposed to grifolin (50 $\mu \mathrm{M}$ ) for $24 \mathrm{~h}$. Data were obtained from three independent experiments. $\beta$-actin was used as a loading control.

$50 \mu \mathrm{M}$ grifolin for $24 \mathrm{~h}$, the number and intensity of punctuate LC3B fluorescence increased as shown in Fig. 4. Next, we investigated the expression of autophagy-related genes by western blot analysis. We found a significant increase in LC3B, Atg7, Beclin-1 and a decrease in P62 in a dose-dependent manner as shown in Fig. 5.

For further studying the role of grifolin in inducing autophagy in human ovarian cancer cell lines, the effect of grifolin on autophagy was confirmed by a GFP-LC3 puncta formation assay. As shown in Fig. 6, we find increased number of GFP-LC3 puncta in the grifolin-treated A2780 and SKOV3 cells.
Next, we used the autophagy inhibitor chloroquine (CQ) to investigate whether grifolin induced ovarian cancer cell death through the induction of autophagy. CQ is a well-known inhibitor of autophagy and inhibits lysosome acidification and degradation (11). We used MTT assay to detect cell viability (as shown in Fig. 7) using $10 \mu \mathrm{M}$ of CQ which was able to significantly reduce the cell death in A2780 and SKOV3 cell lines. To prove the role of LC3B on autophagy in the grifolintreated human ovarian cancer cells, we silenced the expression of LC3B and measured the autophagy level by flow cytometryAVO analysis. As demonstrated in Fig. 8A and B, we found that transfection with shLC3B blocked the autophagic effect of 


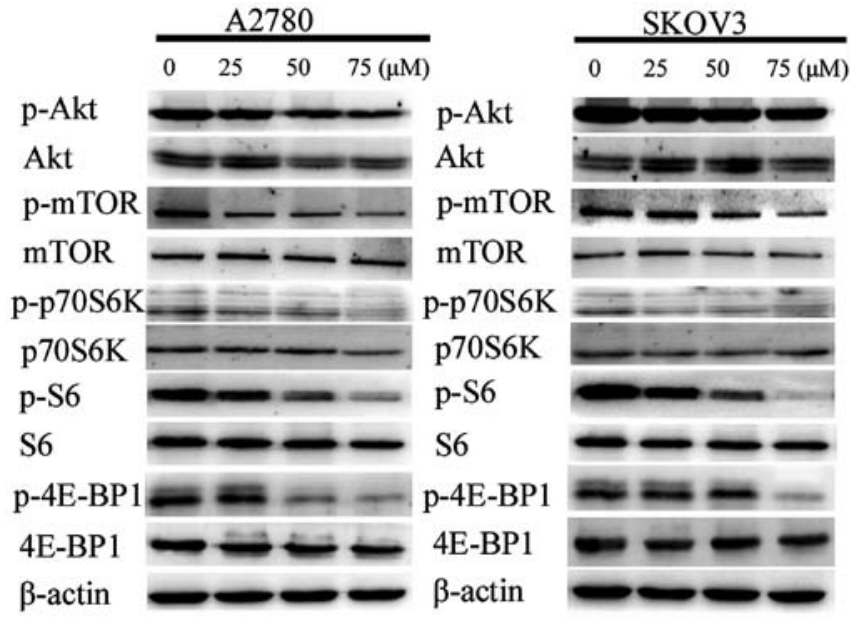

Figure 9. Grifolin inhibits the activity of Akt/mTOR/S6K pathway as detected by western blot analysis. Cells were exposed to grifolin with different concentrations $(0,25,50$ and $75 \mu \mathrm{M})$ for $24 \mathrm{~h}$ and were harvested Results are representative of three independent experiments. $\beta$-actin was used as a loading control.

grifolin-treated A2780 and SKOV3 cells. Then we measured the level of LC3B by western blot analysis. Fig. 8C demonstrates that knockdown of LC3B in A2780 and SKOV3 cells significantly decreased its expression level, and the expression level of LC3B protein in grifolin-treated shLC3B cells expressed was higher than the negative control group. These results suggested that grifolin could reduce autophagic cell death in human ovarian cancer cell lines.

Grifolin inhibits the activity of the Akt/mTOR/S6K pathway. Researchers have found that the inhibition of $\mathrm{Akt} /$ mTOR/S6K pathway is associated with autophagy in various cancer cells (12-14). Thus, we examined whether the pathway is associated with grifolin-treated ovarian cancer cell autophagic death using western blot analysis (Fig. 9). The results demonstrated that grifolin caused a decrease in levels of the phosphorylated form of Akt, mTOR, p70S6K, S6 and $4 \mathrm{E}-\mathrm{BP} 1$ while the total of these proteins remained unaffected by the treatment. Those results suggested that grifolin could induce autophagic cell death by inhibiting the activity of Akt/mTOR/S6K pathway.

\section{Discussion}

In the present study, we investigated the role of autophagy in human ovarian cancer cell lines A2780 and SKOV3 which were treated with grifolin by inhibiting the Akt/mTOR/S6K pathway. This is the first study on the role of grifolin in inducing autophagy in ovarian cancer. A previous study showed that grifolin induced cell cycle arrest in G1 phase via the ERK1/2 pathway (6), and also induced apoptosis through the Bax/Bcl-2 and caspase-3/-9 families via inhibition of PI3K/Akt signalling pathway in human osteosarcoma cells (8). In addition, it has been reported that grifolin upregulated death-associated protein kinase 1 DAPK1 via p53 and mediated G1 phase arrest in nasopharyngeal carcinoma cells $(4,7)$. According to the latest reports, grifolin suppressed cancer cell metastasis by inhibiting ERK1/2 pathway (9).
The Akt/mTOR/S6K pathway plays a significant role in biological functions on various human cancers. A body of evidence proved that Akt is a major component of the Akt/mTOR/S6K pathway and its inactivation promotes cell proliferation and reduces cell death (15). mTOR, a major down-stream target of the pathway, is essential to regulate tumor growth (16). In addition, S6K possesses a key role in cell proliferation and survival (17). The Akt/ mTOR/S6K pathway is becoming an attractive therapeutic target for cancer therapy and its inactivation is reported to occur in various tumors $(18,19)$. Kondo et al $(20)$ found that autophagy is induced mainly through the PI3K/Akt/mTOR pathway. In recent years, many studies demonstrated that the pathway regulates autophagy in various cancers such as breast cancer (21), human hepatocellular carcinoma (22), ovarian cancer (12), melanoma (13), non-small cell lung (23), and nasopharyngeal cancer (14) and the mechanisms of autophagy are well-known. The main mechanism is led by mTOR kinase that acts as an upstream factor of all autophagy-associated genes and regulates transcription and translation (24). The other important mechanism involves the effect of mTOR on two main scaffold proteins the Atg11 and Atg 17, the changes in which lead to activation of Atg1, a key autophagy kinase and then the activated Atg1 is able to affect the output of autophagsome formation (25). In the present study, we investigated that the main proteins of Akt/ mTOR/S6K pathway in grifolin-treated ovarian cancer cells. Our results show that grifolin treatment downregulates phosphorylation of Akt and mTOR and also their downstream targets, p70S6K, S6 and 4E-BP1 while the total proteins have no obvious changes. Those findings prove that grifolin could inhibit autophagy via inhibiting Akt/mTOR/S6K pathway on human ovarian cancer cells.

In summary, we have shown for the first time that grifolin induces autophagic cell death in human ovarian cancer cells by inhibiting the Akt/mTOR/S6K pathway. We provide evidence to prove grifolin could play a role as a novel antitumor agent for human ovarian cancer through the induction of autophagy. However, it is still crucial to explore the responsible molecular mechanisms of grifolin inducing human ovarian cancer cell death.

\section{Acknowledgements}

The present study was partly funded by the National Natural Science Foundation of China (no. 81072121 and no. 81372808 to J.J. and no. 81173614 to Q.T.L) and was also partly funded by the Science and Technology Development Planning of Shandong (no. 2012G0021823 to J.J. and no. 2011 GSF12122 to X.Z and J.J.), the Science and Technology Development Planning of Jinan (201303035) and the Science Foundation of Qilu Hospital of Shandong University (2015QLMS44).

\section{References}

1. Siegel RL, Miller KD and Jemal A: Cancer statistics, 2015. CA Cancer J Clin 65: 5-29, 2015.

2. Quang DN, Hashimoto T, Arakawa Y, Kohchi C, Nishizawa T, Soma G and Asakawa Y: Grifolin derivatives from Albatrellus caeruleoporus, new inhibitors of nitric oxide production in RAW 264.7 cells. Bioorg Med Chem 14: 164-168, 2006. 
3. Liu XT, Winkler AL, Schwan WR, Volk TJ, Rott MA and Monte A: Antibacterial compounds from mushrooms I: A lanostane-type triterpene and prenylphenol derivatives from Jahnoporus hirtus and Albatrellus flettii and their activities against Bacillus cereus and Enterococcus faecalis. Planta Med 76: 182-185, 2010.

4. Luo X, Yu X, Liu S, Deng Q, Liu X, Peng S, Li H, Liu J and Cao Y: The role of targeting kinase activity by natural products in cancer chemoprevention and chemotherapy (Review). Oncol Rep 34: 547-554, 2015.

5. Luo XJ, Li W, Yang LF, Yu XF, Xiao LB, Tang M, Dong X, Deng QP, Bode AM, Liu JK, et al: DAPK1 mediates the G1 phase arrest in human nasopharyngeal carcinoma cells induced by grifolin, a potential antitumor natural product. Eur J Pharmacol 670: 427-434, 2011.

6. Ye M, Luo X, Li L, Shi Y, Tan M, Weng X, Li W, Liu J and Cao Y: Grifolin, a potential antitumor natural product from the mushroom Albatrellus confluens, induces cell-cycle arrest in G1 phase via the ERK1/2 pathway. Cancer Lett 258: 199-207, 2007.

7. Luo XJ, Li LL, Deng QP, Yu XF, Yang LF, Luo FJ, Xiao LB, Chen XY, Ye M, Liu JK, et al: Grifolin, a potent antitumour natural product upregulates death-associated protein kinase 1 DAPK1 via p53 in nasopharyngeal carcinoma cells. Eur J Cancer 47: 316-325, 2011.

8. Jin S, Pang RP, Shen JN, Huang G, Wang J and Zhou JG: Grifolin induces apoptosis via inhibition of PI3K/AKT signalling pathway in human osteosarcoma cells. Apoptosis 12: 1317-1326, 2007.

9. Luo X, Yang L, Xiao L, Xia X, Dong X, Zhong J, Liu Y, Li N Chen L, Li H,et al: Grifolin directly targets ERK1/2 to epigenetically suppress cancer cell metastasis. Oncotarget 6: 42704-42716, 2015.

10. Liang C, Feng P, Ku B, Dotan I, Canaani D, Oh BH and Jung JU: Autophagic and tumour suppressor activity of a novel Beclin1binding protein UVRAG. Nat Cell Biol 8: 688-699, 2006.

11. Mizushima N, Yoshimori T and Levine B: Methods in mammalian autophagy research. Cell 140: 313-326, 2010.

12. Zi D, Zhou ZW, Yang YJ, Huang L, Zhou ZL, He SM, He ZX and Zhou SF: Danusertib induces apoptosis, cell cycle arrest, and autophagy but inhibits epithelial to Mesenchymal transition involving PI3K/Akt/mTOR signaling pathway in human ovarian cancer cells. Int J Mol Sci 16: 27228-27251, 2015.

13. Zhao G, Han X, Zheng S, Li Z, Sha Y, Ni J, Sun Z, Qiao S and Song Z: Curcumin induces autophagy, inhibits proliferation and invasion by downregulating AKT/mTOR signaling pathway in human melanoma cells. Oncol Rep 35: 1065-1074, 2016.
14. Wang KF, Yang H, Jiang WQ, Li S and Cai YC: Puquitinib mesylate (XC-302) induces autophagy via inhibiting the PI3K/ AKT/mTOR signaling pathway in nasopharyngeal cancer cells. Int J Mol Med 36: 1556-1562, 2015.

15. Blanco-Aparicio C, Renner O, Leal J F M and Carnero A: PTEN, more than the AKT pathway. Carcinogenesis 28: 1379-1386, 2007.

16. Fingar DC, Salama S, Tsou C, Harlow E and Blenis J: Mammalian cell size is controlled by mTOR and its downstream targets S6K1 and 4EBP1/eIF4E. Genes Dev 16: 1472-1487, 2002.

17. Harada H, Andersen JS, Mann M, Terada N and Korsmeyer SJ: p70S6 kinase signals cell survival as well as growth, inactivating the pro-apoptotic molecule BAD. Proc Natl Acad Sci USA 98: 9666-9670, 2001

18. Feigin ME, Akshinthala SD, Araki K, Rosenberg AZ, Muthuswamy LB, Martin B, Lehmann BD, Berman HK, Pietenpol JA, Cardiff RD, et al: Mislocalization of the cell polarity protein scribble promotes mammary tumorigenesis and is associated with basal breast cancer. Cancer Res 74: 3180-3194, 2014.

19. Vivanco I and Sawyers CL: The phosphatidylinositol 3-Kinase AKT pathway in human cancer. Nat Rev Cancer 2: 489-501, 2002.

20. Kondo Y, Kanzawa T, Sawaya R and Kondo S: The role of autophagy in cancer development and response to therapy. Nat Rev Cancer 5: 726-734, 2005

21. Wang X, Qi W, Li Y, Zhang N, Dong L, Sun M, Cun J, Zhang Y, Lv S and Yang Q: Huaier extract induces autophagic cell death by inhibiting the mTOR/S6K pathway in breast cancer cells. PLoS One 10: e0131771, 2015.

22. Shi YM, Yang L, Geng YD, Zhang C and Kong LY: Polyphyllin I induced-apoptosis is enhanced by inhibition of autophagy in human hepatocellular carcinoma cells. Phytomedicine 22: $1139-1149,2015$

23. Li YR, Li S, Ho CT, Chang YH, Tan KT, Chung TW, Wang BY, Chen YK and Lin CC: Tangeretin derivative, 5-Acetyloxy-6, 7, 8,4 '-tetramethoxyflavone induces $\mathrm{G} 2 / \mathrm{M}$ arrest, apoptosis and autophagy in human non-small cell lung cancer cells in vitro and In vivo. Cancer Biol Ther 17: 48-64, 2016

24. Wang CW and Klionsky DJ: The molecular mechanism of autophagy. Mol Med 9: 65-76, 2003.

25. Kamber RA, Shoemaker CJ and Denic V: A molecular switch for selective autophagosome formation. Autophagy 11: 2132-2133, 2015. 